Levels and sources of PAHs in selected sites from Portugal biomonitoring with Pinus pinea and Pinus pinaster needles

Ratola, Nuno; Amigo Rubio, Jose Manuel; Alves, Arminda

Published in:

Archives of Environmental Contamination and Toxicology

DOI:

10.1007/s00244-009-9462-0

Publication date:

2010

Document version

Early version, also known as pre-print

Citation for published version (APA):

Ratola, N., Amigo Rubio, J. M., \& Alves, A. (2010). Levels and sources of PAHs in selected sites from Portugal: biomonitoring with Pinus pinea and Pinus pinaster needles. Archives of Environmental Contamination and Toxicology, 58(3), 631-647. https://doi.org/10.1007/s00244-009-9462-0 


\title{
Levels and Sources of PAHs in Selected Sites from Portugal: Biomonitoring with Pinus pinea and Pinus pinaster Needles
}

\author{
Nuno Ratola · José Manuel Amigo • \\ Arminda Alves
}

Received: 15 October 2009/Accepted: 28 December 2009/Published online: 28 January 2010

(C) Springer Science+Business Media, LLC 2010

\begin{abstract}
Pine needle samples from two pine species (Pinus pinaster Ait. and Pinus pinea L.) were collected at 29 sites scattered throughout Portugal, in order to biomonitor the levels and trends of 16 polycyclic aromatic hydrocarbons (PAHs). The values obtained for the sum of all PAHs ranged from 76 to $1944 \mathrm{ng} / \mathrm{g}$ [dry weight (dw)]. Despite the apparent matrix similarities between both pine species, $P$. pinaster needles revealed higher mean entrapment levels than $P$. pinea (748 and $399 \mathrm{ng} / \mathrm{g}$ (dw) per site, respectively). The urban and industrial sites have the highest average of PAH incidence [for $P$. pinea, 465 and $433 \mathrm{ng} / \mathrm{g}$ (dw) per site, respectively, and for P. pinaster, 1147 and $915 \mathrm{ng} / \mathrm{g}(\mathrm{dw})]$, followed by the rural sites [233 ng/g and $711 \mathrm{ng} / \mathrm{g}(\mathrm{dw})$ per site, for $P$. pinea and $P$. pinaster, respectively]. The remote sites, both from $P$. pinaster needles, show the least contamination, with $77 \mathrm{ng} / \mathrm{g}(\mathrm{dw})$ per site. A predominance of 3-ring and 4-ring PAHs was observed in most samples, with phenanthrene having $30.1 \%$ of the total. Naphthalene prevailed in remote sites. Rainfall had no influence on the PAHs levels, but there was a relationship between higher wind speeds and lower concentrations. PAH molecular ratios revealed the influence of both petrogenic and pyrogenic sources.
\end{abstract}

N. Ratola $\cdot$ A. Alves $(\square)$

LEPAE, Departamento de Engenharia Química, Faculdade de Engenharia da Universidade do Porto, Rua Dr. Roberto Frias, 4200-465 Porto, Portugal

e-mail: aalves@fe.up.pt

J. M. Amigo

Department of Food Science, Quality and Technology,

Faculty of Life Sciences, University of Copenhagen,

Rolighedsvej 30, 1958 Frederiksberg C, Denmark
Polycyclic aromatic hydrocarbons (PAHs) are ubiquitous persistent pollutants released into the environment by both natural and anthropogenic sources (Yunker et al. 2002). PAHs are common pollutants in air, water, sediments, and biota, contributing to serious environmental and health problems, including cancer (Jacob 1996; Lapviboonsuk and Loganathan 2007; Mumtaz and George 1995). Furthermore, the release of these contaminants through human activities continues to increase (Lapviboonsuk and Loganathan 2007). The study of PAHs in Portugal is rather recent and is focused on specific locations or processes. The majority of these works concern atmospheric matrixes (Alves et al. 2001; Jaward et al. 2004; Librando et al. 2002; Oliveira et al. 2007; Rocha et al. 1999), sediments (Barreira et al. 2007; Fernández et al. 1999), and mussels (Lima et al. 2007; Serafim et al. 2008), but there are also references to water (Pacheco et al. 2005), landfill leachate (Herbert et al. 2006), and seaweed (Lage-Yusty et al. 2009), along with two previous studies of our group with pine needles, yet focusing mainly on analytical methodologies (Ratola et al. 2006, 2009).

Pine trees are suitable biomonitors for airborne PAHs and other persistent pollutants such as pesticides, polychlorinated biphenyls (PCBs), or polychlorinated naphthalenes (Loganathan et al. 2008). The high wax content of the needles makes them an excellent matrix to preserve accumulated PAHs over time. Trustworthy time-integrated pollution data can be obtained, as well as spatial-related studies (Hwang and Wade 2008; Lehndorff and Schwark 2009a, 2009b).

Portugal is a small country in the southwest of Europe (around $90,000 \mathrm{~km}^{2}$ ), with a little over 10 million inhabitants. The vast majority of the population is distributed along the west coast, with Lisbon (the capital, in the south) and Porto (in the north) as the largest urban and industrial 
centers. The population density decreases drastically toward the interior, where smaller scattered cities and the highest mountains (up to $2000 \mathrm{~m}$ ) exist. Pine trees can be found all over the country, accounting for $33 \%$ of the forested area (DGF 1998). The two most representative pine species in Portugal are Pinus pinaster Ait. and Pinus pinea $\mathrm{L}$.

In this work, pine needles were sampled from 29 different sites scattered through the country and comprising urban, industrial, rural, and remote areas. Total and individual PAH incidence and differences between pine species and site types were studied, in addition to the assessment of potential emitting sources using distribution indexes related to concentration ratios of some PAHs within a given molecular mass (Orecchio et al. 2008). Some considerations on the weather conditions in the sampling sites were also reported. Univariate and multivariate statistics-namely principal component analysis (PCA) - were used in the interpretation of the results.

\section{Materials and Methods}

\section{Chemicals and Reagents}

Standard solutions $(2000 \mu \mathrm{g} / \mathrm{mL})$ of target PAHs [naphthalene (Naph), acenaphthylene (Acy), acenaphthene (Ace), fluorene (Fluo), phenanthrene (Phen), anthracene (Ant), fluoranthene (Flt), pyrene (Pyr), benzo[ $[a]$ anthracene (BaA), chrysene (Chry), benzo[b]fluoranthene $(\mathrm{BbF})$, benzo $[k]$ fluoranthene $(\mathrm{BkF})$, benzo $[a]$ pyrene $(\mathrm{BaP})$, indeno[1,2,3$c d]$ pyrene (IcdP), dibenzo[ $a, h]$ anthracene (DahA), and benzo [ghi]perylene (BghiP)] and deuterated PAHs (naphthalene- $\mathrm{d}_{8}$, acenaphthene- $\mathrm{d}_{10}$, phenanthrene- $\mathrm{d}_{10}$, chrysene- $\mathrm{d}_{12}$ and perylene- $\mathrm{d}_{12}$ ) were purchased from Supelco (Bellefonte, PA, USA), as well as anthracene- $\mathrm{d}_{10}(100 \mu \mathrm{g} / \mathrm{mL})$. International Sorbent Technology (Mid Glamorgan, UK) supplied the SPE alumina cartridges $(5 \mathrm{~g}, 25 \mathrm{~mL})$. Hexane and dichloromethane SupraSolv were from Merck (Darmstadt, Germany) and nitrogen for drying (99.995\% purity) was from Air Liquide (Maia, Portugal). Prior to use, all glass material was silanized in a $15 \%$ dichlorodimethylsilane solution in toluene, both from Aldrich (Milwaukee, WI, USA).

\section{Pine Needles Sampling}

Sampling was conducted in April 2007 and covered 29 sites scattered all over the Portuguese continental territory (Fig. 1). Special care was taken in the selection of the sites, which underwent a rigorous and judicious process according to the logistical means available. It is believed that the chosen sites (and especially their strategic locations) reflected potential differences, as far as biomonitoring is concerned. Hence, the urban sites are represented by 14 of the 18 district capitals of the continental territory (including the largest conurbations, Lisboa and Porto) as are the major industrial complexes (Estarreja, Leça, Outão, Sines and Souselas). Furthermore, 10 rural sites (comprising a population range over 100 and below $10,000)$ also spread through the territory and 2 remote mountain sites (Fóia and Torre) with no population and few anthropogenic interferences were also included.

Second-year needles (with $\sim 2$ years of exposure to contaminants, as new needles burst every year around June) were collected from the two most abundant pine species in Portugal: $P$. pinaster Ait. in 11 sites and $P$. pinea L. in 19 sites. The needles were removed whole, preferably from the bottom (on average, about $2 \mathrm{~m}$ above the ground) and outer branches of the trees. In two cases (Quintãs and Antuã), it was possible to collect samples from contiguous trees of both species. In the other sites, only one tree was sampled. They were wrapped in aluminum foil and placed in sealed plastic bags and immediately frozen and kept in the dark in a cooler. After transportation and storage in the lab, they were defrosted at ambient temperature prior to extraction. The water content measurements were performed with samples defrosted in the same conditions, by drying triplicate 5 -g samples of needles at $80^{\circ} \mathrm{C}$ until constant weight. Table 1 lists some social and economic characteristics of each site (INE 2009) and Table 2 presents the sampling settings and related weather conditions (SNIRH 2009).

\section{Analysis of PAHs}

Needle samples ( $5 \mathrm{~g}$, in duplicate) were extracted by sonication in a 720-W Selecta ultrasonic bath (J.P. Selecta, Barcelona, Spain) with a hexane/dichloromethane (1:1) mixture and purified with alumina solid-phase extraction (SPE) cartridges following a previously described procedure by Ratola et al. (2006). Chromatographic scrutiny of PAHs was performed by a Varian CP-3800 gas chromatograph (Lake Forest, CA, USA) coupled to a Varian 4000 mass spectrometer operating in electron impact mode $(70 \mathrm{eV})$ and a CP-8400 auto-sampler. After a $2-\mu \mathrm{L}$ injection in splitless mode, compound separation was done in a $30-\mathrm{m} \times 0.25$ mm-inner diameter DB-5 column coated with 5\% diphenylpolydimethylsiloxane (film thickness $=0.25 \mu \mathrm{m}$ ) from J\&W Scientific (Folsom, CA, USA) under an oven temperature program that started at $60^{\circ} \mathrm{C}$, was held for $1 \mathrm{~min}$, then increased to $175^{\circ} \mathrm{C}$ at $6^{\circ} \mathrm{C} / \mathrm{min}$, held for $4 \mathrm{~min}$, up to $235^{\circ} \mathrm{C}$ at $3^{\circ} \mathrm{C} / \mathrm{min}$, and, finally, to $300^{\circ} \mathrm{C}$ at $8^{\circ} \mathrm{C} / \mathrm{min}$ and kept for $5 \mathrm{~min}$ until a total run time of $60 \mathrm{~min}$. The temperatures for the injector, transfer line, and ion source were $280^{\circ} \mathrm{C}$, $250^{\circ} \mathrm{C}$, and $200^{\circ} \mathrm{C}$, respectively, and helium $99.9999 \%$ 


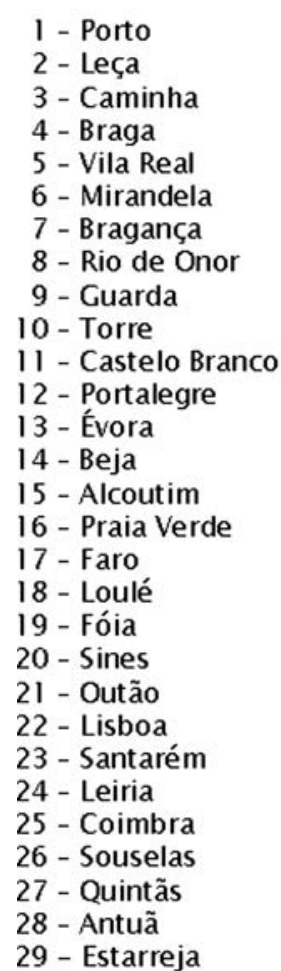

29 - Estarreja

$\begin{array}{ll}\triangle & \text { Urban } \\ \diamond & \text { Industrial } \\ \bigcirc & \text { Rural } \\ \times & \text { Remote }\end{array}$

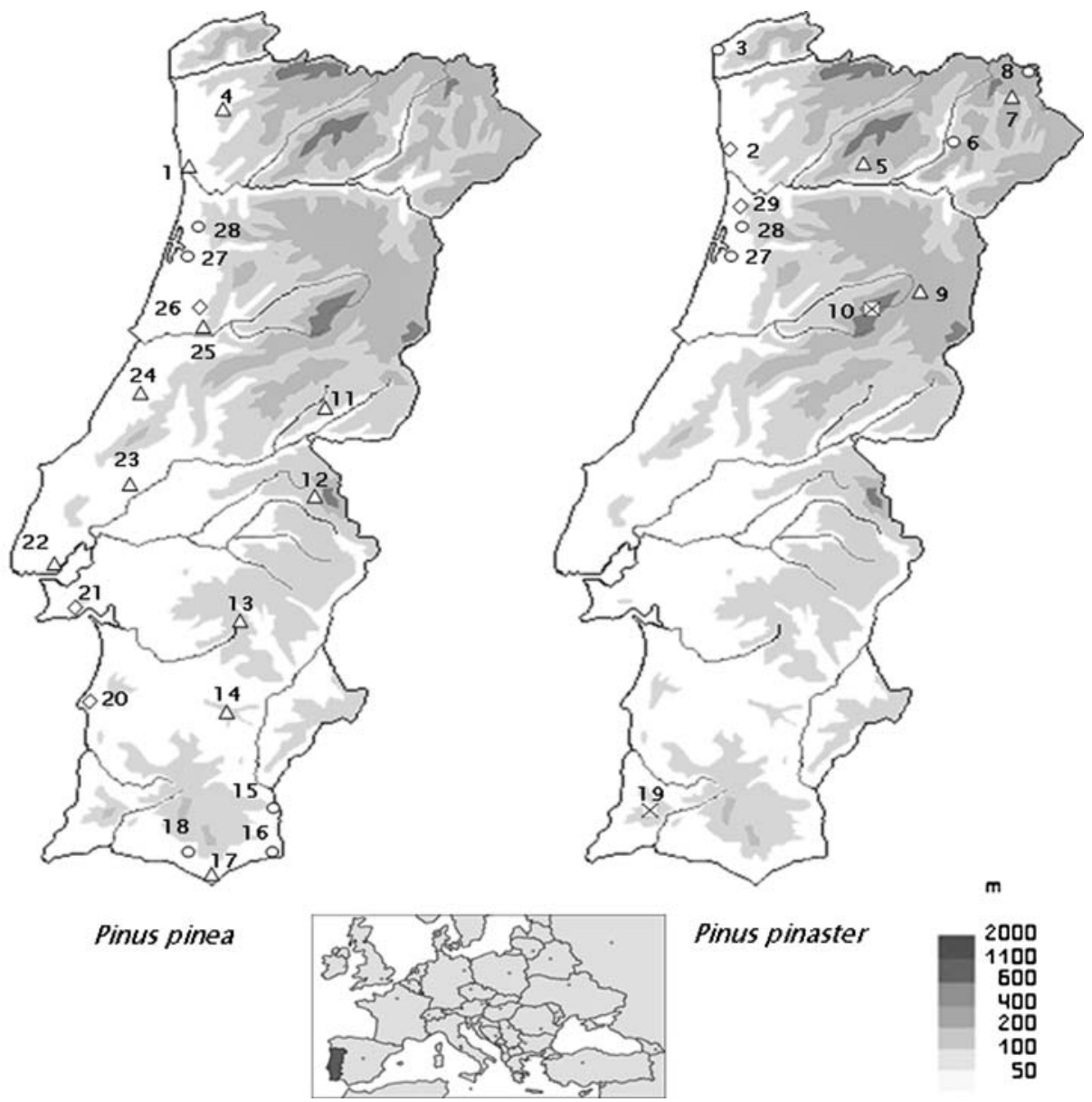

Fig. 1 Location and type of the sampling sites in Portugal

$(1.0 \mathrm{~mL} / \mathrm{min})$ was the carrier gas. Following acquisition in single ion storage (SIS) mode using five retention time windows (each with one deuterated PAH acting as the internal standard), PAHs were identified and quantified with the Mass Spectrometry Workstation 6.6 software from Varian, using retention time and up to three ions (Ratola et al. 2009). Anthracene- $d_{10}$ was spiked in each sample prior to injection, to ascertain possible chromatographic errors.

\section{Method Validation}

All 16 PAHs showed good chromatographic resolution with linear behaviour between 0.01 and $1 \mathrm{mg} \mathrm{L}^{-1}$, except for DahA (0.01-0.75 mg/L). Limits of detection (LODs) were obtained by the signal-to-noise ratio of 3 regarding the direct injection of the least concentrated PAH standard and varied from $0.12 \mathrm{ng} / \mathrm{g}$ [dry weight (dw)] for chrysene to $0.91 \mathrm{ng} / \mathrm{g}(\mathrm{dw})$ for DahA. These values were similar to those reported previously in analogous studies (Martínez et al. 2004; Ratola et al. 2006). The relative standard deviations (RSD\%) for two samples of both species were all below $15 \%$, except for Naph for $P$. pinaster $(16.5 \%)$ and
Fluo for $P$. pinea (18.8\%). Morphological and physiological differences in the needles might have caused the discrepancies found between the two pine species (Piccardo et al. 2005), which nevertheless presented the same water content: $59 \%$.

\section{Statistics}

Univariate ( $F$-test for analysis of variance; independent two-sample $t$-test for unequal sample sizes and unequal variance, and dependent $t$-test for paired samples for a $95 \%$ confidence interval) and multivariate (PCA) statistic tests were applied to the results in order to clarify their interpretation and discussion.

\section{Results and Discussion}

Total and Individual PAH Incidence

The concentrations of PAHs in pine needles collected in Portugal are shown in Table 3. The 16 PAHs in the study 
Table 1 Social and economic characteristics of the sampling sites

\begin{tabular}{|c|c|c|c|c|c|c|c|}
\hline \multirow{2}{*}{$\begin{array}{l}\text { Site No. } \\
22\end{array}$} & \multirow{2}{*}{$\begin{array}{l}\text { Location } \\
\text { Lisboa }\end{array}$} & \multirow{2}{*}{$\begin{array}{l}\text { Site type } \\
\text { Urban }\end{array}$} & \multirow[t]{2}{*}{$\begin{array}{l}\text { Possible point } \\
\text { sources }(<1 \mathrm{~km})\end{array}$} & \multirow{2}{*}{$\begin{array}{l}\text { Population (inhabitants) } \\
564,657\end{array}$} & \multicolumn{2}{|c|}{ 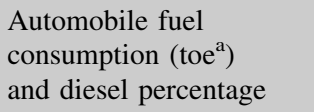 } & \multirow{2}{*}{$\begin{array}{l}\text { Burnt forest } \\
\text { (ha) } \\
3.4\end{array}$} \\
\hline & & & & & 429,139 & (77\% diesel) & \\
\hline 1 & Porto & Urban & & 263,131 & 144,722 & (81\% diesel) & 0.0 \\
\hline 4 & Braga & Urban & & 109,460 & 85,379 & (63\% diesel) & 25.6 \\
\hline 25 & Coimbra & Urban & & 66,729 & 57,387 & (83\% diesel) & 1.5 \\
\hline 24 & Leiria & Urban & & 42,745 & 53,004 & (84\% diesel) & 55.5 \\
\hline 17 & Faro & Urban & & 41,934 & 50,321 & (67\% diesel) & 8.6 \\
\hline 13 & Évora & Urban & & 41,159 & 27,165 & (85\% diesel) & 43.3 \\
\hline 11 & Castelo Branco & Urban & & 30,649 & 15,937 & (68\% diesel) & 29.4 \\
\hline 23 & Santarém & Urban & & 28,760 & 28,472 & (77\% diesel) & 6.3 \\
\hline 9 & Guarda & Urban & & 26,061 & 15,115 & (75\% diesel) & 123.8 \\
\hline 5 & Vila Real & Urban & & 24,481 & 16,647 & (72\% diesel) & 151.4 \\
\hline 14 & Beja & Urban & & 21,658 & 13,645 & (81\% diesel) & 54.4 \\
\hline 7 & Bragança & Urban & Petrol station & 20,309 & 11,373 & (78\% diesel) & 200.8 \\
\hline 12 & Portalegre & Urban & & 15,238 & 7,619 & (66\% diesel) & 3.8 \\
\hline 18 & Loulé & Rural & & 6,736 & 6,332 & (71\% diesel) & 3.6 \\
\hline 27 & Quintãs & Rural & Road construction & 4,780 & 1,434 & (70\% diesel) & 0.1 \\
\hline 3 & Caminha & Rural & & 2,537 & 1,345 & (77\% diesel) & 0.1 \\
\hline 28 & Antuã & Rural & Major highway & 2,320 & 2,830 & (70\% diesel) & 2.3 \\
\hline 16 & Praia Verde & Rural & & 1,920 & 269 & (65\% diesel) & 1.7 \\
\hline 6 & Mirandela & Rural & Landfill & 1,137 & 557 & (82\% diesel) & 1.7 \\
\hline 15 & Alcoutim & Rural & & 1,099 & 407 & (77\% diesel) & 1.8 \\
\hline 8 & Rio de Onor & Rural & & 126 & 71 & (81\% diesel) & 8.8 \\
\hline 10 & Torre & Remote & & 0 & $<71$ & (77\% diesel) & 5.9 \\
\hline 19 & Fóia & Remote & & 0 & $<71$ & (73\% diesel) & 1.2 \\
\hline 2 & Leça & Industrial & Oil refinery & 17,215 & 29782 & (75\% diesel) & 0.0 \\
\hline 21 & Outão & Industrial & $\begin{array}{l}\text { Cement and } \\
\text { co-incineration complex }\end{array}$ & 16,092 & 8851 & (74\% diesel) & 0.0 \\
\hline 20 & Sines & Industrial & Oil refinery & 11,303 & 17746 & (80\% diesel) & 3.5 \\
\hline 29 & Estarreja & Industrial & Chemical complex & 7,794 & 4598 & (81\% diesel) & 1.4 \\
\hline 26 & Souselas & Industrial & $\begin{array}{l}\text { Cement and } \\
\text { co-incineration complex }\end{array}$ & 3,164 & 2721 & (74\% diesel) & 6.6 \\
\hline
\end{tabular}

Note: Shaded area source: INE (2009)

${ }^{\mathrm{a}}$ toe $=$ tons of oil equivalent

were detected in all sites, and the total concentrations varied from $76 \mathrm{ng} / \mathrm{g}$ (dw) in Fóia to $1944 \mathrm{ng} / \mathrm{g}(\mathrm{dw})$ in Bragança. Comparing these results with others published in the literature regarding PAH biomonitoring with pine needles, it can be seen that the values are within the ranges presented (Hwang and Wade 2008; Lehndorff and Schwark 2009b; Librando et al. 2002; Liu et al. 2006; Piccardo et al. 2005; Simonich and Hites 1995; Wenzel et al. 1997).

Individually, Phen was the most concentrated compound in most of the sites, totalling $30.1 \%$ of the PAH contamination. Phen stability is considered high in this type of matrix (Wang et al. 2005) and its dominant presence in similar studies is widely reported. Furthermore, biomonitoring using pine needles is mainly a reflection of atmospheric contamination (Hwang and Wade 2008; Lehndorff and Schwark 2004), and also in these cases, Phen is one of the major atmospheric PAHs. Naph predominated in the sites with lower total PAH concentrations and accounted for $12.8 \%$ in total. In the same contribution range are Fluo (15.3\%), Pyr (13.0\%) and Chyr (11.0\%). On the contrary, Naph is the most volatile PAH in the study, which tends to enhance its mobility due to volatilization from the needles back to the atmosphere, allowing its appearance in more remote locations. Naph is also prone to analytical losses, in particular when evaporation steps are used (Cheng 2003; Piñeiro-Iglesias et al. 2002). 


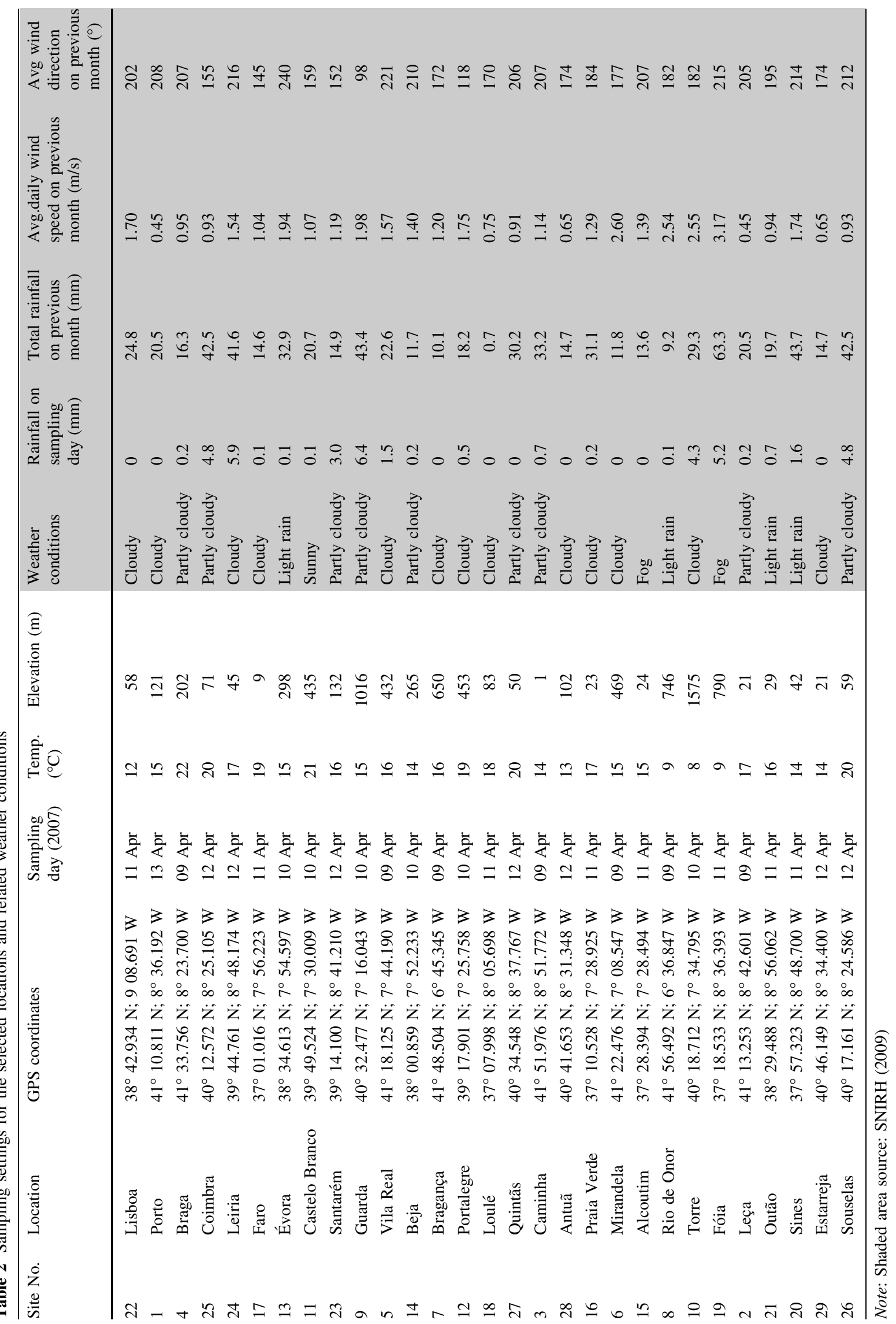




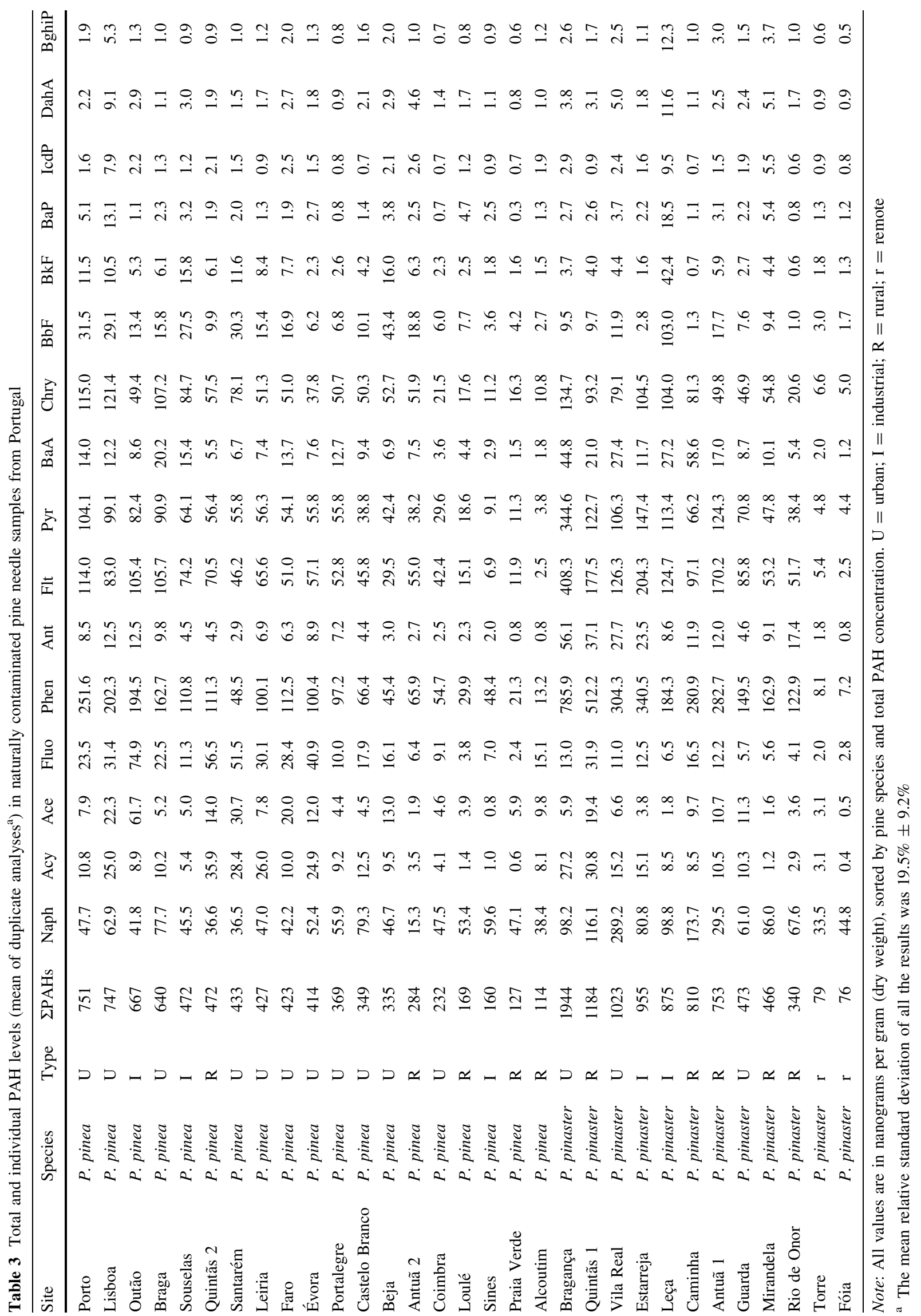




\section{Differences Between Pine Species}

An important finding arises from the comparison between the two pine species. Considering the sites where it was possible to collect needles from two contiguous trees of $P$. pinaster and $P$. pinea (Antuã and Quintãs), it is clear that they presented dissimilar PAH entrapment abilities, as seen in Fig. 2. The greatest difference is in Phen, with almost five times more concentration in $P$. pinaster needles from both sites. Then, in Antuã, Fluo and Pyr have triple the concentration in $P$. pinaster needles, whereas in Quintãs, Naph has triple the concentration, followed by double the Fluo and Pyr values. Interestingly, the main differences between pine species were verified in the PAHs that present higher incidence percentages, considering all sites. This is an indication that $P$. pinaster needles have a stronger adsorption ability toward these PAHs in particular. Statistics confirm these results; dependent $t$-tests for paired samples (95\% confidence interval) show clear differences between the total PAH concentrations of $P$. pinaster and $P$. pinea needles for both Antuã $(t=15.1$, with $t$ critical $=2.13)$ and Quintãs $(t=17.7$, with $t$ critical $=2.13$ )

Considering all of the sites chosen in this work, other evidence of this fact is supported by Fig. 3, which shows the total PAH concentration of each pine species per site and the corresponding aromatic ring patterns. In terms of the percentages by number of rings, the trend is very similar for the two species, with only minor divergences in the 4-ring and 5-ring PAHs. F-Tests for analysis of variance and independent two-sample $t$-tests for unequal sample sizes and unequal variance (for a $95 \%$ confidence interval) confirmed no statistically significant differences. However, it is obvious that the contamination per site is almost double for $P$. pinaster needles [748 vs. $399 \mathrm{ng} / \mathrm{g}$ (dw) for $P$. pinea] and a significant statistical difference between both species was established in this case. Despite the difference in number of sites, both species are well represented by all site types, except for the remote sites, in which only $P$. pinaster trees were collected.

Although not always under the same sampling conditions, other authors have reported similar differences.
Fig. 2 Comparison of individual PAH concentrations between needles of contiguous pine trees from $P$. pinaster and $P$. pinea located in two sites (Antuã and Quintãs)
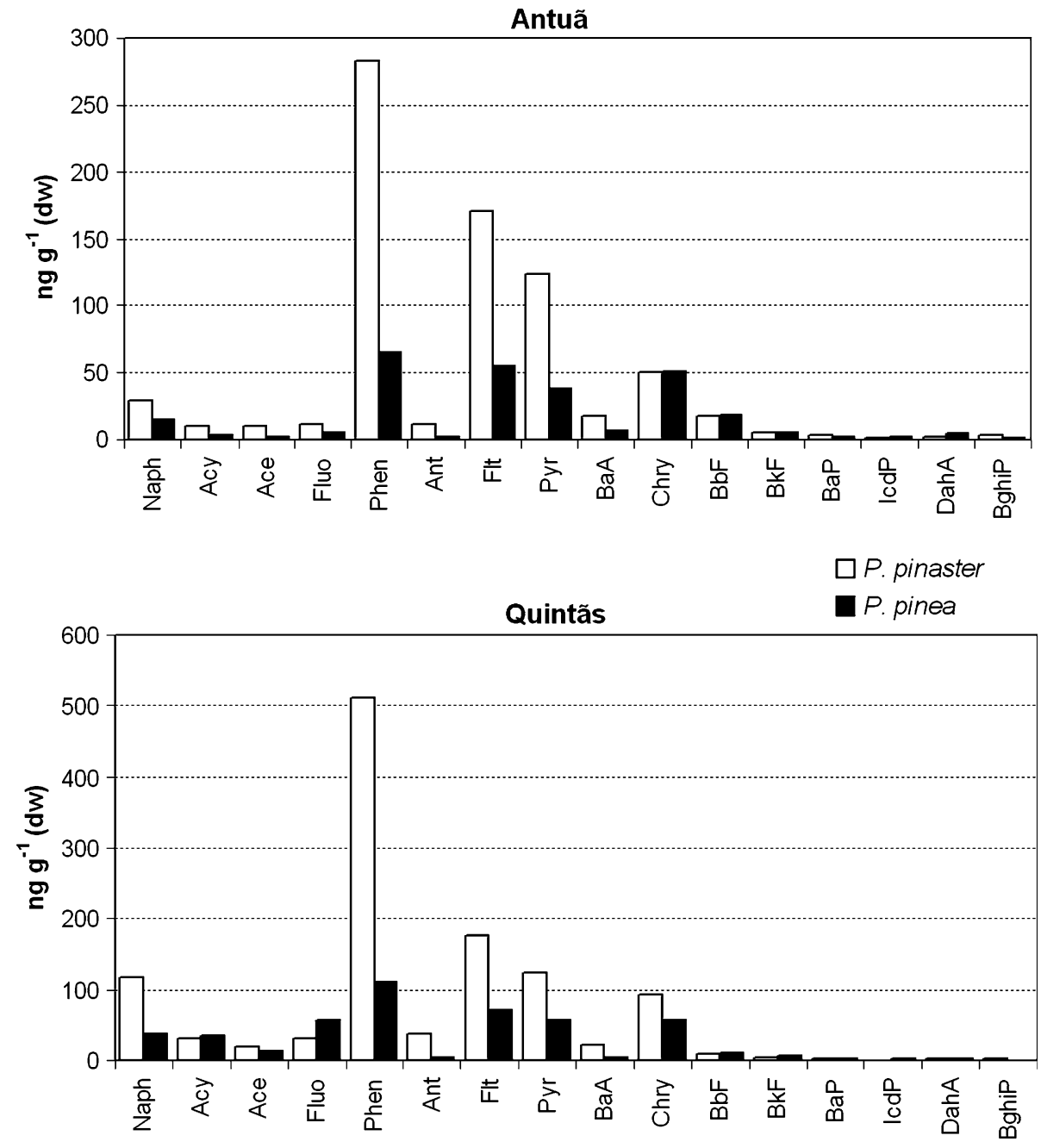
Fig. 3 Mean percent PAHs aromatic rings distribution (columns) and mean total PAHs concentration (points) for $P$. pinaster $(n=12)$ and $P$. pinea $(n=19)$ sites $\square 2$ rings $\square \% 3$ rings $\square \% 4$ rings $\square \% 5$ rings $\square \% 6$ rings

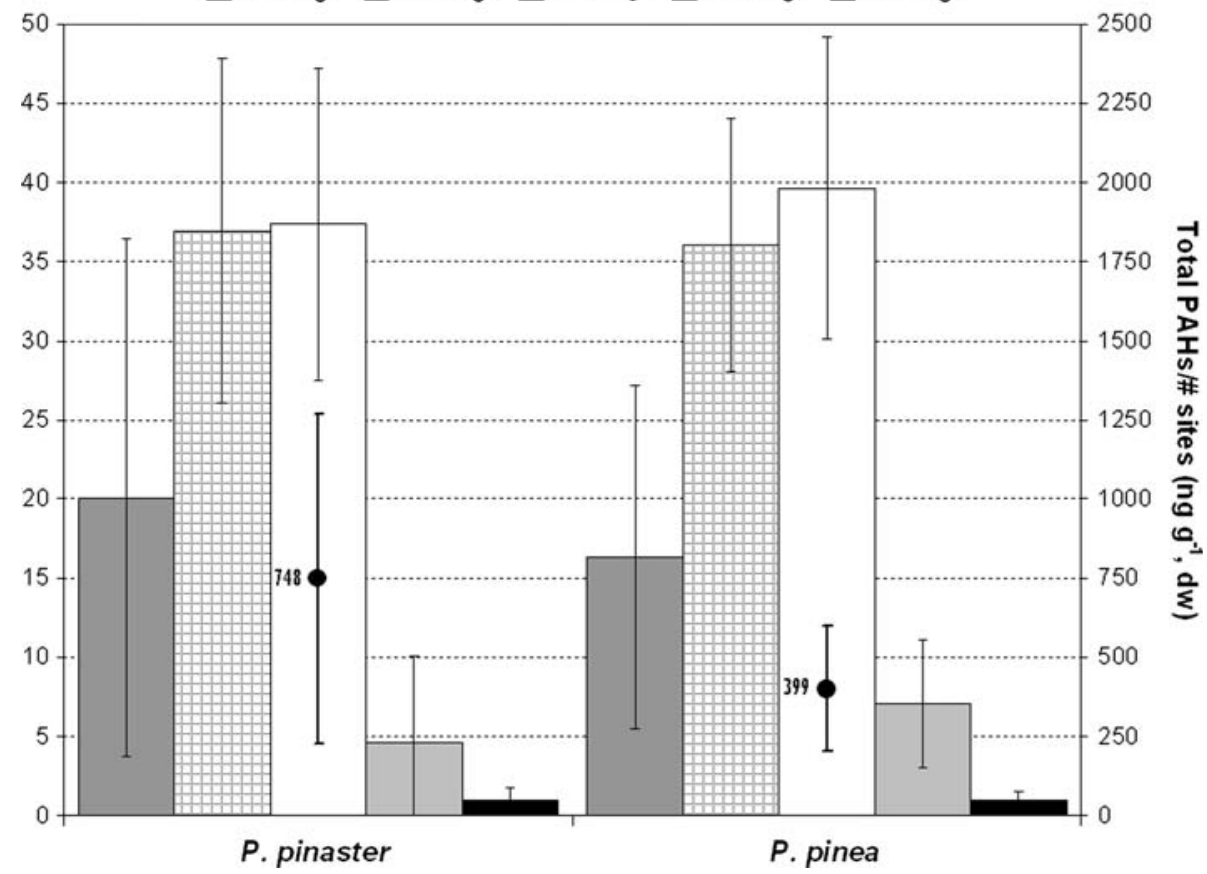

Librando et al. (2002) found global values for P. halepensis higher than for $P$. pinea needles, whereas Piccardo et al. (2005) reported a greater affinity of $P$. pinaster needles toward PAHs compared to $P$. nigra.

Hence, all further discussion of the results of this study takes these differences into account and both pine species are considered separately.

\section{Pinus pinea Sites}

Considering only the $P$. pinea sites, the contamination trend meets the expectations, as both sites with the highest levels are the two largest urban conurbations in Portugalnamely Porto and the capital Lisboa, with almost identical total PAH concentrations [751 and $747 \mathrm{ng} / \mathrm{g}$ (dw), respectively]. Outão (an important industrial spot to the south of Lisboa), Braga (the second most populated district capital in the north of the country after Porto), Souselas (another important industrial center), and Quintãs 2 follow in descending order of concentration. Quintãs is a small village on the outskirts of Aveiro (an important city in the north coast of the country) and can be considered a rural setting. In this case, the construction and subsequent opening of a major road in the vicinity of the sampling point might have been the cause for the highest PAH concentration among rural sites. The remaining $P$. pinea sites are in smaller urban and rural settings, mainly in the south of the country, where the population density is lower and the local anthropogenic sources of PAHs are expected to have a lesser impact. The case of Sines is noteworthy.
Despite being an industrial zone, it is situated in a rather isolated area and, apparently, the local sources do not play a very important role, given the low PAH incidence [167 ng/g (dw)].

\section{Pinus pinaster Sites}

The needles collected in the seven sites with the highest overall PAH levels are from P. pinaster trees. Bragança is the largest urban area in the northeast of Portugal but is nonetheless a small city in an area of scarce industrial activity. This value might be a consequence of the particular location of the sampled pine, in the city center with major traffic incidence and next to a busy gas station. There is also the possibility that this particular pine tree might have, itself, for a number of conditioning and structural factors, a much higher capacity of PAH entrapment than other $P$. pinaster trees. Quintãs 1 presents the second highest PAH concentration. As seen in $P$. pinea needles (Quintãs 2), this is the rural site with higher PAH incidence. Following Bragança and Quintãs, Vila Real has similar characteristics to the first and Estarreja and Leça are heavy industry spots in which a high prevalence of PAHs is expected. Caminha is a seaside village on the extreme northwest of the country, which might have some PAH occurrence from the maritime traffic across the river border to Spain and from wood combustion in the small forest from which the needles were collected. Antuã, on the side of a major highway, as mentioned earlier, receives emissions from the heavy traffic. The other $P$. pinaster sites 
are Guarda, the most elevated district capital, in the interior, Mirandela, a rural site near a landfill facility, and Rio de Onor, a very small village in a deep rural environment on the northeast extreme of Portugal. The two sites with the least PAH concentrations are also $P$. pinaster but are considered remote in this study (Torre and Fóia). Being both isolated mountain sites, very low contamination levels were expected.

\section{Study by Site Type}

In an attempt to portray the patterns of the PAH incidence, Fig. 4 shows the distribution according to the number of aromatic rings and the mean PAH levels per site in each of the four site types chosen in this study and for both pines species separately.

As expected, the urban and industrial sites have the predominant mean PAH incidence [for $P$. pinea, 465 and $433 \mathrm{ng} / \mathrm{g}(\mathrm{dw})$ per site, respectively, and for $P$. pinaster, 1147 and $915 \mathrm{ng} / \mathrm{g}(\mathrm{dw})$ ], followed by the rural sites [233 and $711 \mathrm{ng} / \mathrm{g}(\mathrm{dw})$ per site for $P$. pinea and P. pinaster, respectively]. The remote sites, only two and both from $P$. pinaster needles, present clearly the lowest contamination, with $77 \mathrm{ng} / \mathrm{g}(\mathrm{dw})$ per site. These results also reinforce the idea of the higher PAH entrapment ability of $P$. pinaster needles over $P$. pinea needles. Considering each species separately, $P$. pinaster presented significantly statistical differences only between the remote sites and each
Fig. 4 Percent PAHs aromatic rings distribution (columns) and total PAHs concentration per site (points) for the combination of urban $(n=14 ; 11$ P. pinea, 3 $P$. pinaster $)$, industrial $(n=5 ; 3$ $P$. pinea, $2 P$. pinaster), rural ( $n=10 ; 5$ P. pinea, $5 P$. pinaster $)$, and remote $(n=2$, $P$. pinaster) sites
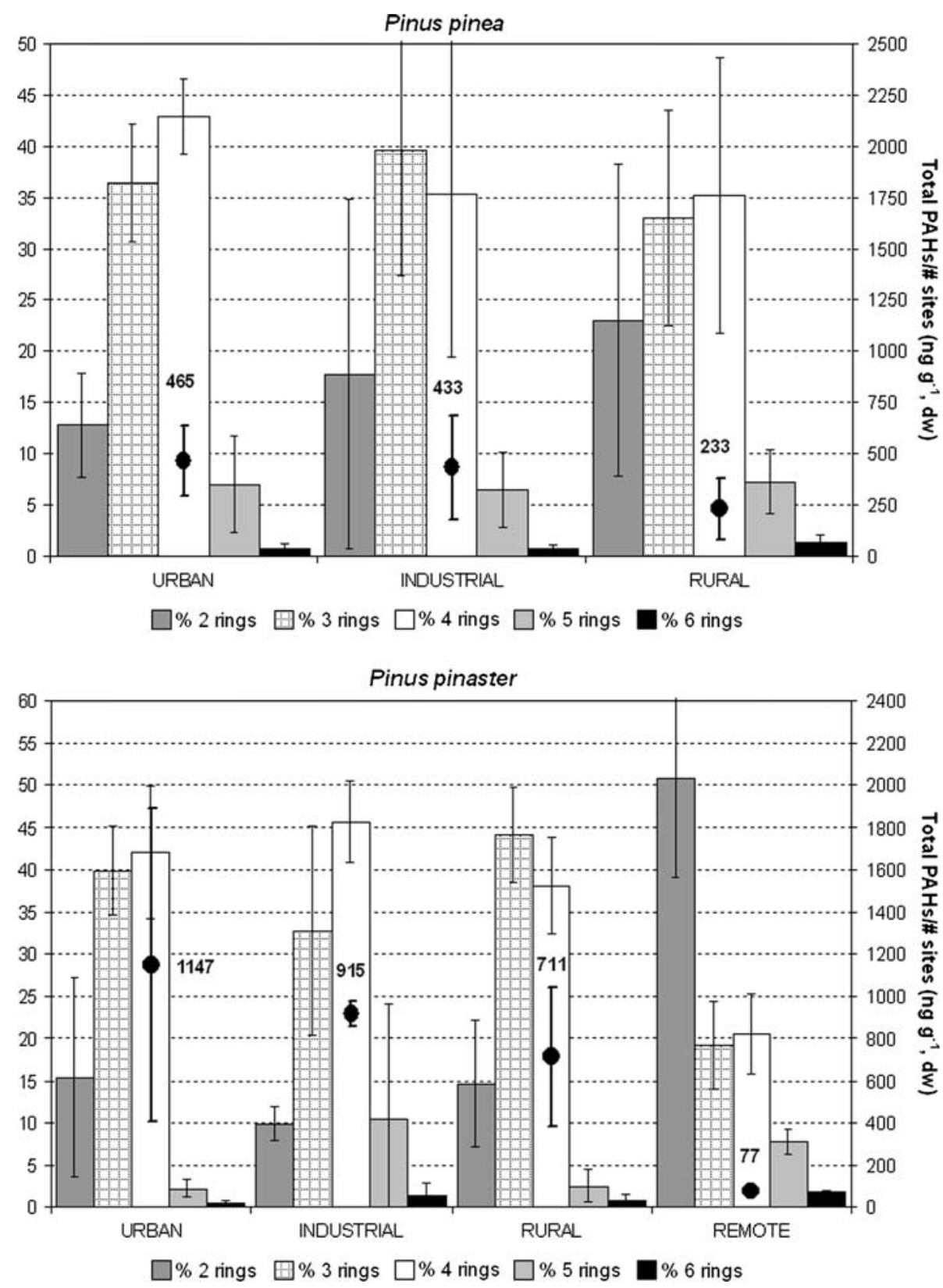
of the other site types, whereas for $P$. pinea, no differences occurred, except between the urban and the rural sites, and only for the $t$-test for comparison of means.

Similar levels were presented previously in the literature, such as by Tremolada et al. (1996), who found an average of $323 \mathrm{ng} / \mathrm{g}(\mathrm{dw})$ for rural sites, or Lang et al. (2000), who reported average concentrations of $92 \mathrm{ng} / \mathrm{g}$ (dw) for mountain (remote) sites and $703 \mathrm{ng} / \mathrm{g}$ (dw) for urban sites. Even when the PAH incidence is globally higher or lower, the trends for the site types coincide. For instance, Piccardo et al. (2005) reported lower overall concentrations but a common tendency (urban $>$ rural $>$ remote), whereas Tian et al. (2008) found higher contamination, but with the urban and industrial sites with similar levels and above those for rural sites. For seventeen 3-ring PAHs, Lehndorff and Schwark (2009b) obtained an industrial $>$ urban $>$ rural trend, with similar levels for each site type.

The PAH distribution according to the number of aromatic rings is, however, not so different among urban, industrial, and rural sites. Statistical tests confirm this observation, for both $P$. pinea and $P$. pinaster sites and for all of the PAHs grouped by number of rings. Only the differences between the mean ring percentages of remote sites and each of the other types are statistically significant, according to $F$-tests and $t$-tests. Tables 4 and 5 summarize the results of the statistics tests applied to the comparison of site types and number of aromatic rings. There is a predominance of either 3- or 4-ring PAHs (between 30\% and $45 \%$, depending on the case), with the largest difference shown in industrial sites with $P$. pinaster trees, where 4-ring PAHs dominate by over $10 \%$. These values are expected because the main PAH uptake process onto the waxy layer of the needles is gaseous absorption from the atmosphere, where more than $95 \%$ of the 3- and 4-ring PAHs occur in the vapor phase (Hwang and Wade 2008). The heaviest PAHs are generally removed from the air by direct (e.g., wet) deposition processes (Blasco et al. 2006). These PAHs are closely linked with motorized traffic, in general, and diesel fuel consumption, in particular (Blasco et al. 2006; Hwang et al. 2003; Marr et al. 1999). This is the case of Phen, Fluo, and Pyr, some of the dominant PAHs in this study. Considering its population, the traffic density in Portugal is not negligible, even in the smaller cities and rural areas. As a result of the higher tax burden applied to gasoline, diesel motors are very common, even in the lighter vehicles. As can be seen in Table 1, 65-85\% of the automobile fuel consumption in the areas of the sampling sites corresponds to diesel engines. This is probably the major source of PAH incidence in the country. Hwang et al. (2003) also reported the predominance of 4-ring PAHs in Mexico City, where there is also a high number of heavy-duty vehicles lacking emission control catalysts, whereas in Korea and in Texas (USA), 3-ring PAHs presented a higher incidence. Migaszewski et al. (2002) found a $3>4>5>6$ ring sequence in needles from rural areas. Low-molecular-weight PAHs (two and three rings) are common in fresh fuels (Masclet et al. 1987), combustion activities (Singh et al. 2008), and some industrial emissions (Yang et al. 1998). In this case, Naph is the only 2-ring PAH studied; hence, the percentages between $10 \%$ and $25 \%$ found for urban, industrial, and rural sites have some relevance on a per-compound basis. Although the possibility of light vehicular traffic (Guidotti et al. 2003) and gasoline engines, in particular (Khalili et al. 1995), as sources of Naph was reported, Preuss et al. (2003) referred to it as a constituent of diesel fuels and a product of forest fires. One explanation for the strong prevalence of this contaminant in the remote sites (above $50 \%$ ) might arise from the fact that diesel-powered engines are predominant in rural and remote areas (trucks and tractors). In the latter, these are probably the only PAH sources, along with forest fires. Naph has a strong presence in these cases and its percentage might be higher in remote locations than in more urbanized areas. Another possibility could derive from the evidence that Naph is the most volatile of all PAHs studied, which could enhance traveling from distant sources. However, Preuss et al. (2003) indicated that these movements can be counteracted by its proneness to photochemically induced degradation. The pattern for remote sites is then clearly different, because in this case the 3- and 4- ring PAHs have around 20\% incidence each. The high-molecular-weight PAHs (five and six rings) are associated with traffic and industrial activities (Orecchio et al. 2008) as well as with combustion processes (Singh et al. 2008). This is reflected in the highest incidence of these PAHs in industrial sites from $P$. pinaster needles (over 10\%). Surprisingly, the percentage of these groups in remote locations has a very similar level, surpassing the urban and rural areas. Lee et al. (2005) suggested that DahA is also an indicator of remote traffic emissions, which can be one of the causes for this behavior. The 6-ring PAHs have the smallest contribution to the overall incidence (below 2\%).

\section{Considerations on the Weather Conditions}

It is known that weather conditions play an important role in the PAH distribution in the environmental matrixes. Because the sampling campaign was carried out in a period with some rainfall, it was important to find out if there was some effect on the PAH levels. Information about the total rainfall in the sampling date and in the month previous to sample collection is presented in Table 2, as well as information on average wind speed and direction. 
Arch Environ Contam Toxicol (2010) 58:631-647

641

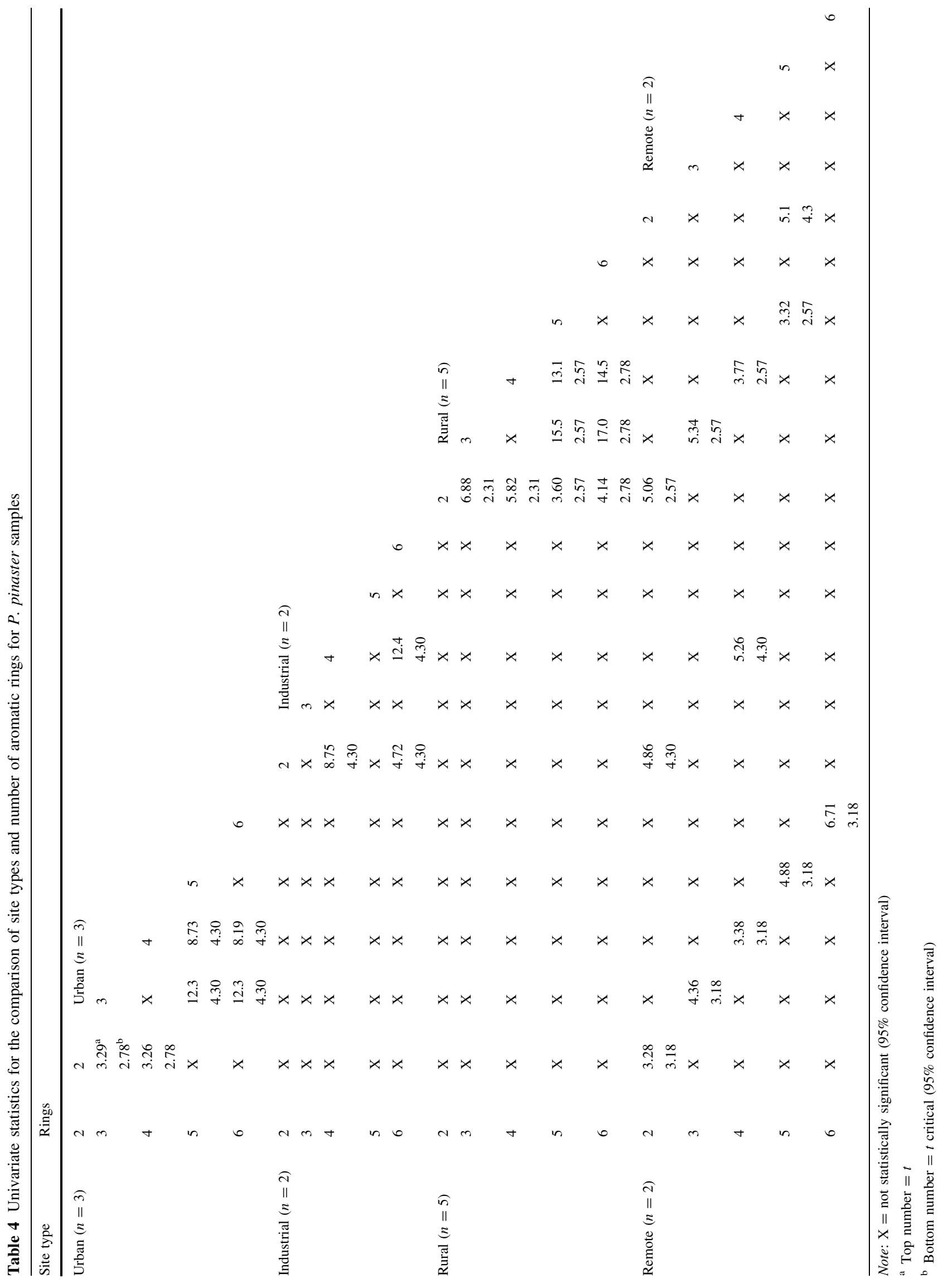

Springer 


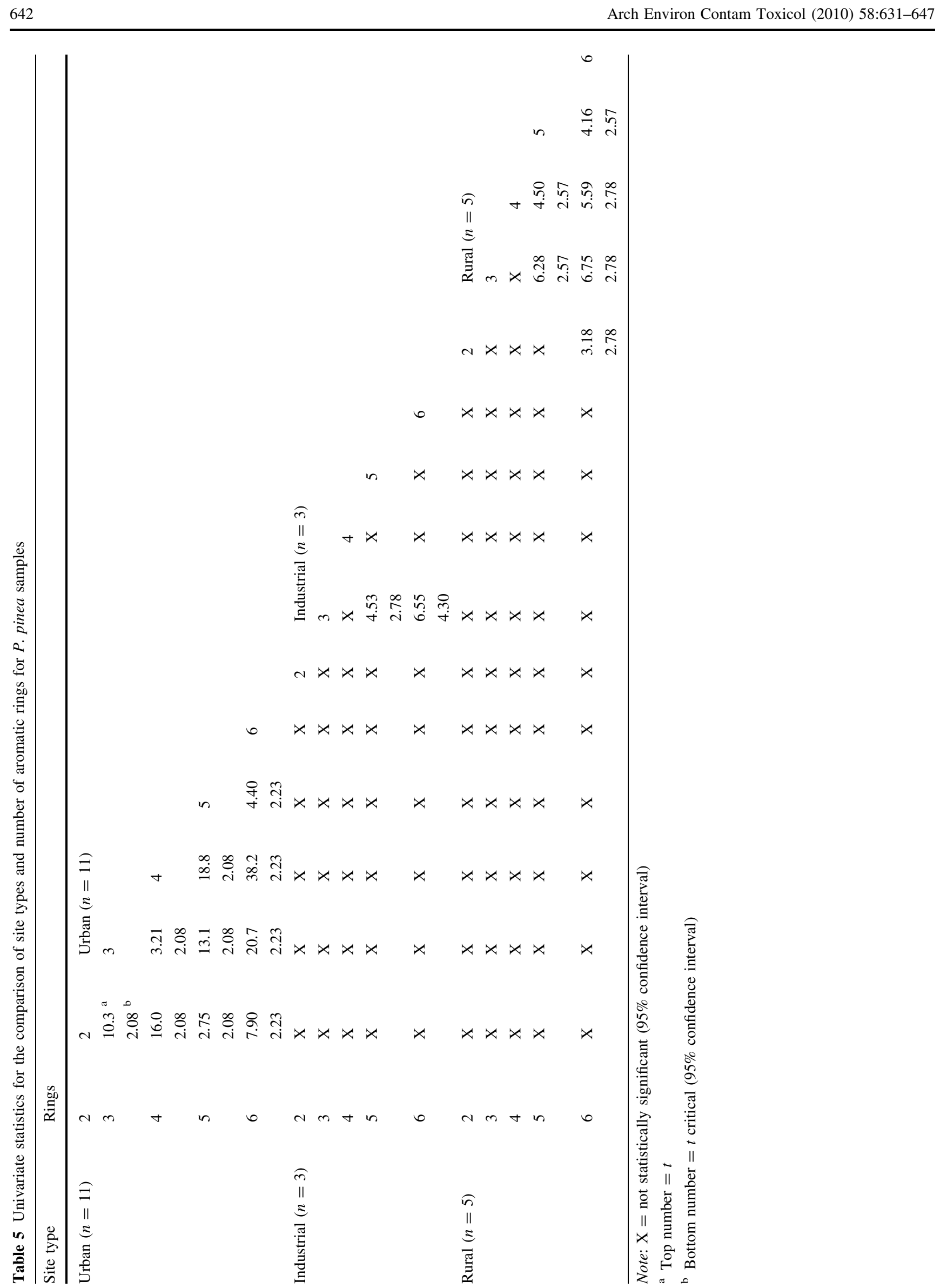

Springer 
The dry and wet depositions are two main routes of PAHs incidence in pine needles and are also dependent on weather parameters. According to Simonich and Hites (1995), both gaseous and particulate pollutants reaching the needles by these processes are rapidly sorbed onto the superficial waxy layer, diffusing then in a much slower fashion into the inner compartments. Niu et al. (2003) reported the possibility of the most volatile PAHs being more prone to accumulation inside the waxy layer of the needle, whereas the heaviest PAHs (commonly associated with particles) remain in the surface, more easily exposed to external conditions, such as wind abrasion (Horstmann and McLachlan 1998) and wash-off by rainfall (Srogi 2007). Nevertheless, Lehndorff and Schwark (2004) stated that the majority of the particle-bound PAHs will remain in the needles. On the other hand, rainfall episodes contribute to the deposition of both gaseous and particle-bound PAHs, although with a higher incidence in the latter case (Baek et al. 1991). Smith and Jones (2000) found that most particles are washed out from the atmosphere at the beginning of the event, which means that rainfall can have a washingoff effect that overcomes or at least competes with the deposition processes, depending on the amount of precipitation. Using Norway spruce needles, Brorström-Lundén and Löfgren (1998) found no relationship between rainfall and the PAH concentrations in needles. Studies done in deciduous tree leaves (such as oak or hazel) revealed different conclusions. Howsam et al. (2001) reported that rainfall was negatively correlated with the levels of the heaviest PAHs, whereas Alfani et al. (2005) showed no influence of rain in the total PAH concentrations in the leaves. Furthermore, De Nicola et al. (2008) found no difference in the PAH levels of washed and unwashed leaves. Dry deposition is more dependent on other parameters, such as wind and the physical adherence onto the surface of the needles (Smith and Jones 2000) and is greatly dependent on the particle size. Ravindra et al. (2008) stated that dry deposition rules in the case of particle-bound heavier PAHs, whereas the lighter ones appear in the rain mainly as a solute.

In the current work, at the time of the collection, it was raining only in four sites, and with low intensity (Table 2). Nevertheless, it was possible to collect only dry needles in all sites, once second year needles are more "protected" from light rainfall episodes.

Of these four sites, Rio de Onor is a rural site with a little over 100 inhabitants, so low PAH incidence would be expected, Évora has medium contamination regarding the $P$. pinea range, and Outão is one of the most highly contaminated among the samples of the same species. Sines seems to be the only one to present a low value in view of its location near an industrial complex. However, as seen in Table 2, there were other rainfall episodes near some of the other sampling locations during the sample day. It is impossible to ascertain if that amount of rain took place before or after the sampling or in both cases. Still, looking at the values of precipitation (both in the sampling day and in the previous month), there is no clear relation with the total PAH concentration in the chosen sites.

Interestingly, in terms of the daily mean wind velocity for the month previous to the sampling day (Table 2), the sites with strongest winds have a more visible relationship with those with less $\mathrm{PAH}$ contamination, especially for $P$. pinaster. PCA reinforces these conclusions (Fig. 5). A matrix with 19 row samples for $P$. pinea and 12 row samples for $P$. pinaster (the respective sampling sites) and 4 column variables (total PAHs concentration, amount of rain on the sampling day, rain accumulation in the month prior to sampling day, and average wind speed in the month prior to sampling day) was built in this case. Plotting PC1 and PC2, which explain $87.7 \%$ of the variability for $P$. pinaster sites and $71.6 \%$ for $P$. pinea sites, it can be seen that both species present similar results. The loadings plots (on the right of Fig. 5) show that the rain parameters are poorly related with the $\mathrm{PAH}$ concentration, but they also reveal that the wind speed is indeed in opposite quadrants of the plot, relating, in general, the lower PAH levels to the windiest sites. Of course, these sites are also those with less population and nearby PAH sources, a fact that might dilute this apparent trend. The wind effect is very difficult to measure, especially because the direction might play a crucial role. Mean values for this parameter are also presented in Table 2 and apparently there is no relationship with the $\mathrm{PAH}$ incidence in these sites, with one exception. Sines has perhaps one of the most unexpected $\mathrm{PAH}$ values, according to the site- type ranking. However, in this case, the tree sampled was in the middle of an open field with no traffic or houses nearby and to the west of the industrial complex (upwind). As seen in Table 2, the prevailing winds are in a north-south direction, which might prevent exposure to higher levels in that particular tree.

In view of these elements and of the PAH levels obtained in this work, it is very difficult to establish a general effect of rainfall and wind or a distinction between the influence of dry and wet deposition. Because no historical temperature records were available for most sampling locations, it was impossible to determine the effect of this equally important parameter.

\section{PAH Source Assessment}

The sources of PAHs produce fingerprints in the form of molecular patterns. Pyrolytic (or pyrogenic) PAHs present a wide range of molecular weights, whereas petroleum (or petrogenic) PAHs have a predominance of the lowestmolecular-weight kind (Baumard et al. 1998). In order to 

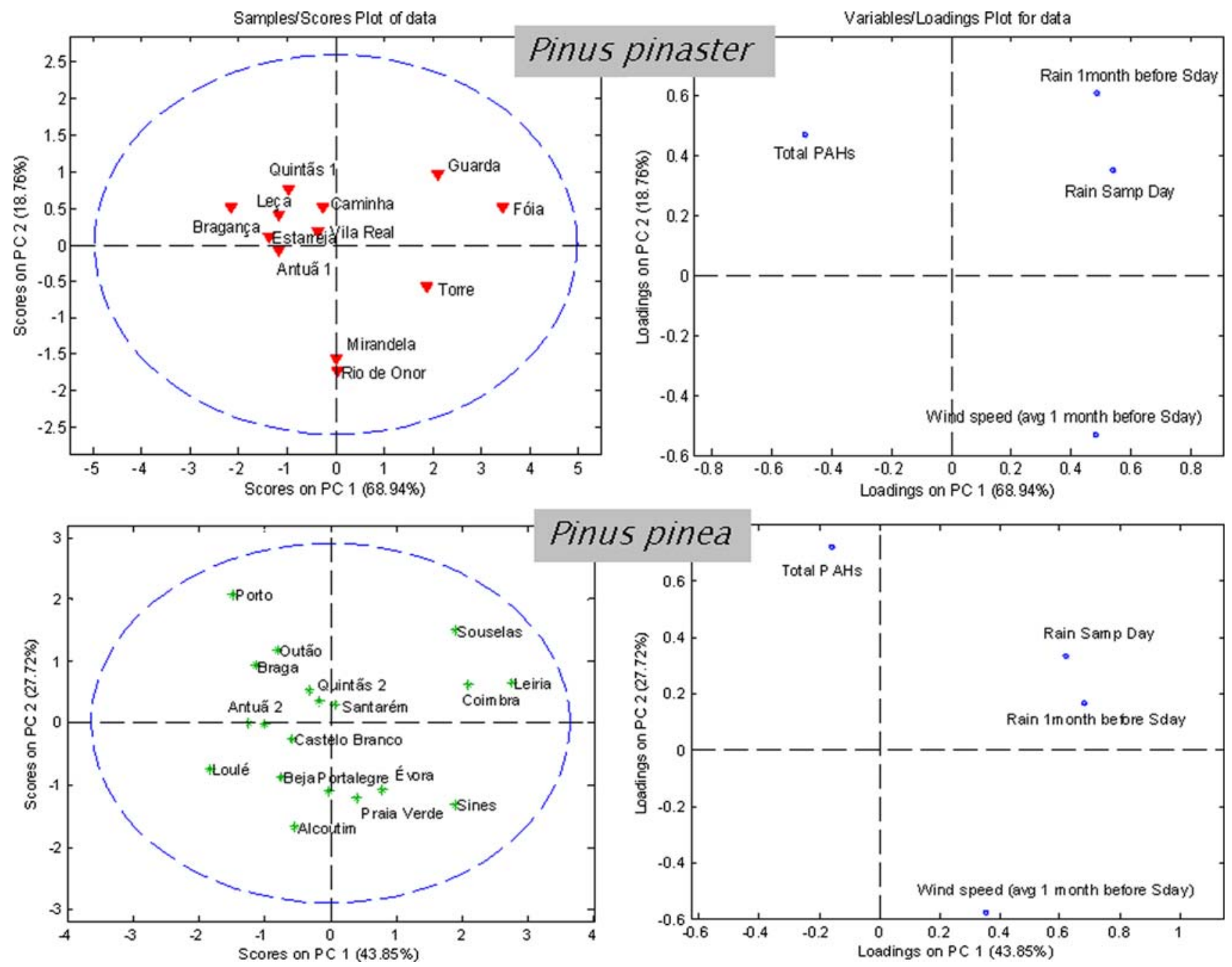

Fig. 5 Scores and loadings plots for PC 1 and PC 2 from P. pinaster and P. pinea samples (scores: sampling sites; loadings: weather conditions and total PAH concentration)

assess some of these sources or groups of sources, individual PAH ratios have been studied by several authors in different matrixes, including pine needles (Hwang et al. 2003; Lehndorff and Schwark 2004; Yunker et al. 2002). These evaluations are performed under the assumption that structurally isomeric PAHs undergo similar environmental behavior and/or transformations in their route from the emitting sources to the final contaminated location (Zhang et al. 2005). This is a rather risky assumption given the complexity of the processes involved and so, to allow a more accurate identification of the sources, combined ratios are often used (Hwang et al. 2003). One of the most often used combinations is to plot the Phen/Ant ratio (PAHs of molecular mass 178) against the Flt/Pyr ratio (molecular mass $=202$ ), which can make a distinction between pyrogenic and petrogenic sources (Orecchio et al. 2008). Phen/Ant ratios below 10 and Flt/Pyr ratios above 1 suggest pyrogenic sources, whereas petrogenic appear in the opposite ranges (Baumard et al. 1998).

In Fig. 6, the ratios represent the mean of each site type and the corresponding $x$ and $y$ standard deviation bars, in order to clarify the "clouds of influence" of each type. In $P$. pinea needles, all sites are in the petrogenic area, although the urban sites are slightly closer to the pyrogenic boundary in the case of the Phen/Ant ratio, whereas for Flt/ Pyr, all of them are exactly on that boundary. The first evidence for $P$. pinaster needles is that there is a clear separation between the remote sites and the others, which have very similar areas among themselves (with the rural sites more toward the pyrogenic side in the Flt/Pyr ratio). Nevertheless, no statistically significant differences were found between site types for the values of Phen/Ant and Flt/Pyr in both pine species. All site types are situated in plot zones in which both types of sources intertwine, 
Fig. 6 Phen/Ant versus Flt/Pyr to determine possible $\mathrm{PAH}$ contamination sources for each site type $(X=$ remote;

$\bullet=$ rural; $\diamond=$ industrial; $\Delta=$ urban)
Pinus pinea

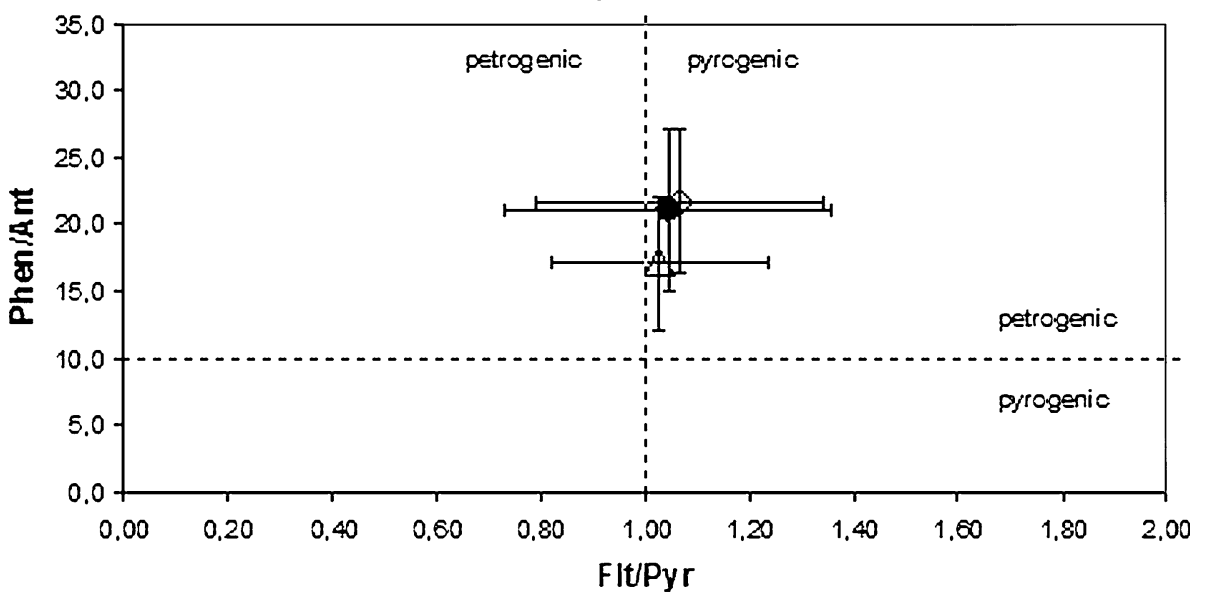

Pinus pinaster

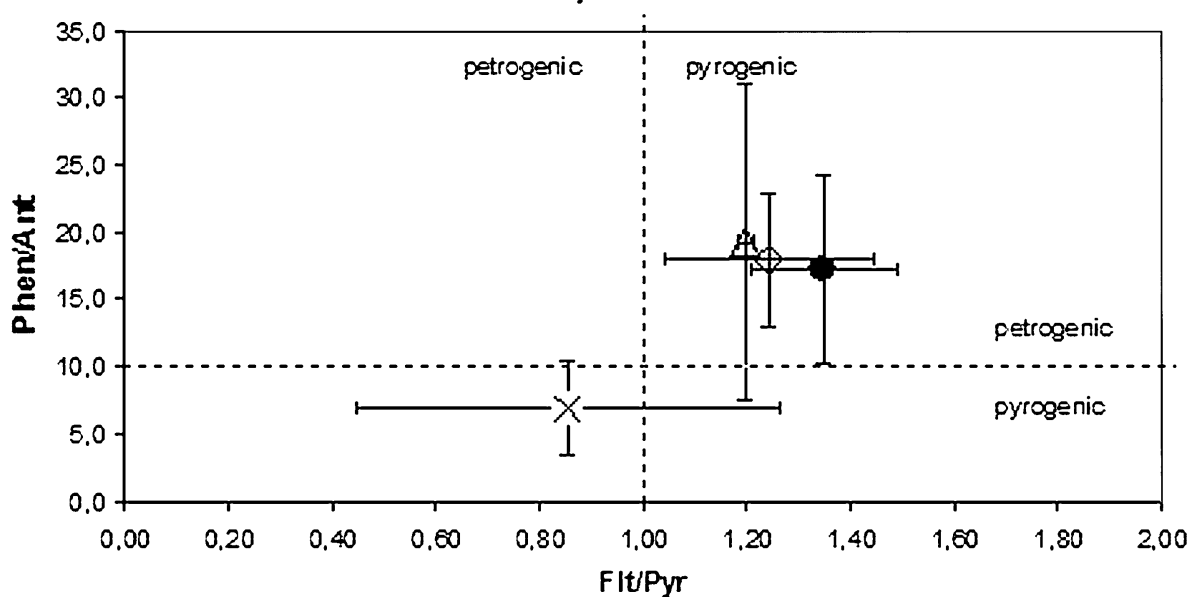

corresponding to mixed origins. This observation is reinforced by the fact that the mean ratios associated with each of the four site types point toward a contradiction of sources. Still, because Phen is much stabler in pine needles and less prone to photodegradation than Ant, high Phen/ Ant ratios might indicate either the mentioned Ant decay in the needles or the existence of more traveled sources (Hwang et al. 2003). This can emphasize the previously mentioned possibility that the sources of the scarce contamination observed in the remote sites are local and of pyrogenic origin, such as forest fires or limited traffic. The antagonistic indication of the Flt/Pyr in this case suggests petrogenic sources instead, which is in line with the high percentage of Naph present in these locations; this compound is often a significant fraction of crude oils and petroleum products (Yang 2000). The results reported by Lehndorff and Schwark (2004) fall predominantly in the same quadrant of the cross-plot, also pointing toward mixed sources. However, the behavior of PAHs depends on the type of receiving matrix. For instance, they are much stabler in sediments than in air or vegetation samples (Hwang et al. 2003). In fact, some authors admit that the use of these ratios should in some cases be independent of the matrix (Hwang et al. 2003), whereas others stress the inaccuracy of such an assumption (Zhang et al. 2005). All of them, however, agree that extreme care must be taken in the interpretation of the results obtained. This can suggest that potentially opposite findings can at the same time be complementary, especially when dealing with a high number of possible different sources. The influence of traveling PAHs in the contamination of a given pine tree might be difficult to assess. Although the sites were classified according to the predominant land use in the sampling areas, distant sources might also affect those results.

\section{Conclusions}

The sampling plan was executed in order to assess the incidence and trends of contamination of 16 PAHs in pine needles. Hence, 29 sites were selected in urban, industrial, rural, and remote areas of Portugal, and pine trees from two different species ( $P$. pinaster Ait. and $P$. pinea L.) were chosen. Overall, the values obtained ranged from 
$76 \mathrm{ng} / \mathrm{g}$ (dw) in Fóia to $1944 \mathrm{ng} / \mathrm{g}$ (dw) in Bragança. $P$. pinaster needles revealed a stronger entrapment affinity toward PAHs than $P$. pinea $[748$ and $399 \mathrm{ng} / \mathrm{g}(\mathrm{dw})$ per site, respectively]. Thus, both species were analyzed separately. On a per-site basis, the industrial and urban sites (mostly near the coastline) presented the highest mean contamination [for $P$. pinea, 465 and $433 \mathrm{ng} / \mathrm{g}$ (dw) per site, respectively, and for $P$. pinaster, 1147 and $915 \mathrm{ng} / \mathrm{g} \mathrm{(dw)],} \mathrm{followed} \mathrm{by} \mathrm{the} \mathrm{rural} \mathrm{sites} \mathrm{[233} \mathrm{and}$ $711 \mathrm{ng} / \mathrm{g}(\mathrm{dw})$ per site for $P$. pinea and $P$. pinaster, respectively]. The remote areas, both from $P$. pinaster, showed the lowest levels [77 ng/g (dw) per site]. Phen was the most concentrated PAH, with $30.1 \%$ of the total contamination, and a predominance of 3-ring and 4-ring PAHs was found in the majority of samples. However, in remote sites, Naph (the only 2-ring PAH in study) had a stronger incidence. There is no influence of rainfall on the PAHs levels, but higher wind speeds tend to be related to lower concentrations. Wind direction might have a particular influence in the case of Sines. PAH molecular ratios pointed toward the influence of both petrogenic and pyrogenic sources but with a recognizable cross-plot separation between remote and the other site types on the $P$. pinaster samples.

Acknowledgments The authors wish to thank Fundação para a Ciência e a Tecnologia (Portugal) for the scholarship SFRH/BD/ $11970 / 2002$ and the project PTDC-AGR-CFL-73156/06. Dr. Olga Ferreira is thanked for her collaboration in the collection of the samples.

\section{References}

Alfani A, De Nicola F, Maisto G, Prati MV (2005) Long-term PAH accumulation after bud break in Quercus ilex L. leaves in a polluted environment. Atmos Environ 39:307-314

Alves C, Pio C, Duarte A (2001) Composition of extractable organic matter of air particles from rural and urban Portuguese areas. Atmos Environ 35:5485-5496

Baek SO, Field RA, Goldstone ME, Kirk PW, Lester JN, Perry R (1991) A review of atmospheric polycyclic aromatic hydrocarbons: sources, fate and behaviour. Water Air Soil Pollut 60:279300

Barreira LA, Mudge SM, Bebianno MJ (2007) Concentration and sources of polycyclic aromatic hydrocarbons in sediments from the Ria Formosa Lagoon. Environ Forensics 3:231-243

Baumard P, Budzinski H, Garrigues P (1998) Polycyclic aromatic hydrocarbons in sediments and mussels of the western Mediterranean Sea. Environ Toxicol Chem 17:765-776

Blasco M, Domeño C, Nerín C (2006) Use of lichens as pollution biomonitors in remote areas: comparison of PAHs extracted from lichens and atmospheric particles sampled in and around the Somport tunnel (Pyrenees). Environ Sci Technol 40:6384-6391

Brorström-Lundén E, Löfgren C (1998) Atmospheric fluxes of persistent semivolatile organic pollutants to a forest ecological system at the Swedish west coast and accumulation in spruce needles. Environ Pollut 102:139-149
Cheng CC (2003) Recovery of polycyclic aromatic hydrocarbons during solvent evaporation with a rotary evaporator. Polycyclic Aromat Compd 32:315-325

De Nicola F, Maisto G, Prati MV, Alfani A (2008) Leaf accumulation of trace elements and polycyclic aromatic hydrocarbons (PAHs) in Quercus ilex L. Environ Pollut 153:376-383

DGF (Direcção-Geral das Florestas) Ministério da Agricultura (1998) Inventário florestal nacional. Portugal continental-3 ${ }^{\mathrm{a}}$ Revisão:1995-1998. Direcção-Geral das Florestas, Lisboa

Fernández P, Vilanova RM, Grimalt JO (1999) Sediment fluxes of polycyclic aromatic hydrocarbons in European high altitude mountain lakes. Environ Sci Technol 33:3716-3722

Guidotti M, Stella D, Owczarek M, De Marco A, De Simone C (2003) Lichens as polycyclic aromatic hydrocarbon bioaccumulators used in atmospheric pollution studies. J Chromatogr A 985:185190

Herbert P, Silva AL, João MJ, Santos L, Alves A (2006) Determination of semi-volatile priority pollutants in landfill leachates and sediments using microwave-assisted headspace solid-phase microextraction. Anal Bioanal Chem 386:324-331

Horstmann M, McLachlan MS (1998) Atmospheric deposition of semivolatile organic compounds to two forest canopies. Atmos Environ 32:1799-1809

Howsam M, Jones KC, Ineson P (2001) PAHs associated with the leaves of three deciduous tree species. II: uptake during a growing season. Chemosphere 44:155-164

Hwang HH, Wade TL (2008) Aerial distribution temperaturedependent seasonal variation and sources of polycyclic aromatic hydrocarbons in pine needles from the Houston metropolitan area Texas USA. J Environ Sci Health A 43:1243-1251

Hwang HH, Wade TL, Sericano JL (2003) Concentrations and source characterization of polycyclic aromatic hydrocarbons in pine needles from Korea, Mexico and United States. Atmos Environ 37:2259-2267

INE (Instituto Nacional de Estatística-Statistics Portugal) (2009) www.ine.pt. Assessed 25 May 2009

Jacob J (1996) The significance of polycyclic aromatic hydrocarbons as environmental carcinogens. Pure Appl Chem 68:301-308

Jaward FM, Farrar NJ, Harner T, Sweetman AJ, Jones KC (2004) Passive air sampling of polycyclic aromatic hydrocarbons and polychlorinated naphthalenes across Europe. Environ Toxicol Chem 23:1355-1364

Khalili NR, Scheff PA, Holsen TM (1995) PAH source fingerprints for coke ovens diesel and gasoline engines highway tunnels and wood combustion emissions. Atmos Environ 29:533-542

Lage-Yusty MA, Alvarez-Pérez S, Punín-Crespo MO (2009) Supercritical fluid extraction of polycyclic aromatic hydrocarbons from seaweed samples before and after the Prestige oil spill. Bull Environ Contam Toxicol 82:158-161

Lang Q, Hunt F, Wai CM (2000) Supercritical fluid extraction of polycyclic aromatic hydrocarbons from white pine (Pinus strobus) needles and its implications. J Environ Monit 2:639644

Lapviboonsuk J, Loganathan BG (2007) Polynuclear aromatic hydrocarbons in sediments and mussel tissue from the lowermost Tennessee River and Kentucky Lake. J KY Acad Sci 68:186197

Lee RGM, Coleman P, Jones JL (2005) Emission factors and importance of PCDD/Fs PCBs PCNs PAHs and PM10 from the domestic burning of coal and wood in the UK. Environ Sci Technol 39:1436-1447

Lehndorff E, Schwark L (2004) Biomonitoring of air quality in the Cologne Conurbation using pine needles as a passive samplerpart II: polycyclic aromatic hydrocarbons (PAH). Atmos Environ 38:3793-3808 
Lehndorff E, Schwark L (2009a) Biomonitoring airborne parent and alkylated three-ring PAHs in the Greater Cologne Conurbation I: temporal accumulation patterns. Environ Pollut 157:1323-1331

Lehndorff E, Schwark L (2009b) Biomonitoring airborne parent and alkylated three-ring PAHs in the Greater Cologne Conurbation II: regional distribution patterns. Environ Pollut 157:1706-1713

Librando V, Perrini G, Tomasello M (2002) Biomonitoring of atmospheric PAHs by evergreen plants: correlations and applicability. Polycyclic Aromat Compd 22:549-559

Lima I, Moreira SM, Osten JRV, Soares AMVM, Guilhermino L (2007) Biochemical responses of the marine mussel Mytilus galloprovincialis to petrochemical environmental contamination along the North-western coast of Portugal. Chemosphere 66:1230-1242

Liu GQ, Zhang G, Li J, Li XD, Peng XZ, Qi SH (2006) Spatial distribution and seasonal variations of polycyclic aromatic hydrocarbons (PAHs) using semi-permeable membrane devices (SPMD) and pine needles in the Pearl River Delta South China. Atmos Environ 40:3134-3143

Loganathan BG, Kumar KS, Seaford KD, Sajwan KS, Hanari N, Yamashita N (2008) Distribution of persistent organohalogen compounds in pine needles from selected locations in Kentucky and Georgia, USA. Arch Environ Contam Toxicol 54:422-439

Marr LC, Kirchstetter TW, Harley RA, Miguel AH, Hering SV, Hammond SK (1999) Characterization of polycyclic aromatic hydrocarbons in motor vehicle fuels and exhaust emissions. Environ Sci Technol 33:3091-3099

Martínez E, Gros M, Lacorte S, Barceló D (2004) Simplified procedures for the analysis of polycyclic aromatic hydrocarbons in water sediments and mussels. J Chromatogr A 1047:181-188

Masclet P, Bresson MA, Mouvier G (1987) Polycyclic aromatic hydrocarbons emitted by power stations and influence of combustion conditions. Fuel 66:556-562

Migaszewski ZM, Gałuszka A, Pasławski P (2002) Polynuclear aromatic hydrocarbons phenols and trace metals in selected soil profiles and plant bioindicators in the Holy Cross Mountains South-Central Poland. Environ Int 28:303-313

Mumtaz M, George J (1995) Toxicological profile for polycyclic aromatic hydrocarbons (PAHs). US Department of Human and Health Services. Agency for Toxic Substances and Disease Registry, Atlanta, GA

Niu J, Chen J, Martens D, Quan X, Yang F, Kettrup A, Schramm KW (2003) Photolysis of polycyclic aromatic hydrocarbons adsorbed on spruce [Picea abies (L.) Karst.] needles under sunlight irradiation. Environ Pollut 123:39-45

Oliveira C, Pio C, Alves C, Evtyugina M, Santos P, Gonçalves V, Nunes T, Silvestre AJ, Palmgren F, Wahlin P, Harrad S (2007) Seasonal distribution of polar organic compounds in the urban atmosphere of two large cities from the North and South of Europe. Atmos Environ 41:5555-5570

Orecchio S, Gianguzza A, Culotta L (2008) Absorption of polycyclic aromatic hydrocarbons by Pinus bark: analytical method and use for environmental pollution monitoring in the Palermo area (Sicily Italy). Environ Res 107:371-379

Pacheco M, Santos MA, Teles M, Oliveira M, Rebelo JE, Pombo L (2005) Biotransformation and genotoxic biomarkers in mullet species (Liza sp.) from a contaminated coastal lagoon (Ria de Aveiro Portugal). Environ Monit Assess 107:133-153

Piccardo MT, Pala M, Bonaccurso B, Stella A, Redaelli A, Paola G, Valério F (2005) Pinus nigra and Pinus pinaster needles as passive samplers of polycyclic aromatic hydrocarbons. Environ Pollut 133:293-301

Piñeiro-Iglesias M, López-Mahía P, Vázquez-Blanco E, MuniateguiLorenzo S, Prada-Rodríguez D (2002) Problems in the extraction of polycyclic aromatic hydrocarbons from diesel particulate matter. Polycyclic Aromat Compd 22:129-146
Preuss R, Angerer J, Drexler H (2003) Naphthalene-an environmental and occupational toxicant. Int Arch Occup Environ Health 76:556-576

Ratola N, Lacorte S, Alves A, Barceló D (2006) Analysis of polycyclic aromatic hydrocarbons in pine needles by gas chromatography mass spectrometry: comparison of different extraction and cleanup procedures. J Chromatogr A 1114:198-204

Ratola N, Lacorte S, Barceló D, Alves A (2009) Microwave-assisted extraction and ultrasonic extraction to determine polycyclic aromatic hydrocarbons in needles and bark of Pinus pinaster. Ait and Pinus pinea L. by GC-MS. Talanta 77:1120-1128

Ravindra K, Sokhi R, Van Grieken R (2008) Atmospheric polycyclic aromatic hydrocarbons: source attribution, emission factors and regulation. Atmos Environ 42:2895-2921

Rocha TAP, Horvath H, Oliveira JABP, Duarte AC (1999) Trends in alkanes and PAHs in airborne particulate matter from Oporto and Vienna: identification and comparison. Sci Total Environ 236:231-236

Serafim A, Lopes B, Company R, Ferreira AM, Bebianno MJ (2008) Comparative petroleum hydrocarbons levels and biochemical responses in mussels from hydrothermal vents (Bathymodiolus azoricus) and coastal environments (Mytilus galloprovincialis). Marine Pollut Bull 57:529-537

Simonich SL, Hites RA (1995) Organic pollutant accumulation in vegetation. Environ Sci Technol 29:2095-2103

Singh KP, Malik A, Kumar R, Saxena P, Sinha S (2008) Receptor modelling for source apportionment of polycyclic aromatic hydrocarbons in urban atmosphere. Environ Monit Assess 136:183-196

Smith KEC, Jones KC (2000) Particles and vegetation: implications for the transfer of particle-bound organic contaminants to vegetation. Sci Total Environ 246:207-236

SNIRH (Sistema Nacional de Informação de Recursos HídricosPortugal) (2009) http://snirh.pt/snirh.php?main_id=2\&item $=0$ \&idioma=english. Assessed 23 July 2009

Srogi K (2007) Monitoring of environmental exposure to polycyclic aromatic hydrocarbons: a review. Environ Chem Lett 5:169-195

Tian X, Liu J, Zhou G, Peng P, Wang X, Wang C (2008) Estimation of the annual scavenged amount of polycyclic aromatic hydrocarbons by forests in the Pearl River Delta of Southern China. Environ Pollut 156:306-315

Tremolada P, Burnett V, Calamari D, Jones KC (1996) Spatial distribution of PAHs in the UK atmosphere using pine needles. Environ Sci Technol 30:3570-3577

Wang DG, Chen JW, Xu Z, Qiao XL, Huang LP (2005) Disappearance of polycyclic aromatic hydrocarbons sorbed on surfaces of pine [Pinus thunbergii] needles under irradiation of sunlight: volatilization and photolysis. Atmos Environ 39:4583-4591

Wenzel K-D, Weißflog L, Paladini E, Gantuz M, Guerreiro P, Puliafito C, Schüürmann G (1997) Immission patterns of airborne pollutants in Argentina and Germany II. Biomonitoring of organochlorine compounds and polycyclic aromatics. Chemosphere 34:2505-2518

Yang G-P (2000) Polycyclic aromatic hydrocarbons in the sediments of the South China Sea. Environ Pollut 108:163-171

Yang H-H, Lee W-J, Chen S-J, Lai S-O (1998) PAH emission from various industrial stacks. J Hazard Mater 60:159-174

Yunker MB, Macdonald RW, Vingarzan R, Mitchell RH, Goyette D, Sylvestre S (2002) PAHs in the Fraser River basin: a critical appraisal of PAH ratios as indicators of PAH source and composition. Org Geochem 33:489-515

Zhang XL, Tao S, Liu WX, Yang Y, Zuo Q, Liu SZ (2005) Source diagnostics of polycyclic aromatic hydrocarbons based on species ratios: a multimedia approach. Environ Sci Technol 39:9109-9114 